\title{
Combined neutrophil-lymphocyte ratio and platelet-lymphocyte ratio predicts chemotherapy response and prognosis in patients with advanced gastric cancer
}

Tetsushi Hirahara ${ }^{1 \dagger}$, Takaaki Arigami ${ }^{2^{*+}} \mathbb{D}$, Shigehiro Yanagita ${ }^{1}$, Daisuke Matsushita ${ }^{1}$, Yasuto Uchikado ${ }^{1}$, Yoshiaki Kita ${ }^{1}$, Shinichiro Mori ${ }^{1}$, Ken Sasaki ${ }^{1}$, Itaru Omoto ${ }^{1}$, Hiroshi Kurahara', Kosei Maemura', Keishi Okubo', Yoshikazu Uenosono ${ }^{1}$, Sumiya Ishigami ${ }^{1}$ and Shoji Natsugoe ${ }^{1,2}$

\begin{abstract}
Background: The neutrophil-lymphocyte ratio (NLR) and platelet-lymphocyte ratio (PLR) are representative blood markers of systemic inflammatory responses. However, the clinical significance of the combination of these markers is unclear. This study aimed to investigate the NLR and PLR in patients with advanced gastric cancer treated with chemotherapy and assess the clinical utility of a new blood score combining the NLR and PLR (NLR-PLR score) as a predictor of tumor response and prognosis.

Methods: We retrospectively analyzed 175 patients with gastric cancer receiving chemotherapy or chemoradiotherapy. These patients were categorized into progressive disease (PD) and non-PD groups according to tumor response. The NLR and PLR before treatment were examined, and the cut-off values were determined. The NLR-PLR score ranged from 0 to 2 as follows: score of 2, high NLR (> 2.461) and high PLR (> 248.4); score of 1, either high NLR or high PLR; score of 0 , neither high NLR nor high PLR.

Results: With regard to tumor response, 64 and 111 patients had PD and non-PD, respectively. The NLR-PLR score was significantly higher in patients with PD than in those with non-PD $(p=0.0009)$. The prognosis was significantly poorer in patients with a higher NLR-PLR score than in those with a lower NLR-PLR score $(p<0.0001)$. Multivariate analysis demonstrated that the NLR-PLR score was an independent prognostic factor for prediction of overall survival ( $p=0.0392)$.

Conclusion: Low-cost stratification according to the NLR-PLR score might be a promising approach for predicting tumor response and prognosis in patients with advanced gastric cancer.
\end{abstract}

Keywords: Neutrophil-lymphocyte ratio, Platelet-lymphocyte ratio, Chemotherapy response, Prognosis, Advanced gastric cancer

\section{Background}

Gastric cancer is one of the most common gastrointestinal malignancies and is the third leading cause of cancerrelated mortality worldwide [1]. Currently, various therapeutic strategies are available for the clinical management

\footnotetext{
* Correspondence: arigami@m.kufm.kagoshima-u.ac.jp

${ }^{\dagger}$ Tetsushi Hirahara and Takaaki Arigami contributed equally to this work. ${ }^{2}$ Department of Onco-biological Surgery, Kagoshima University Graduate School of Medical and Dental Sciences, 8-35-1 Sakuragaoka, Kagoshima 890-8520, Japan

Full list of author information is available at the end of the article
}

of patients with early gastric cancer having a favorable prognosis. In particular, endoscopic treatments, such as endoscopic submucosal dissection, have been widely accepted as minimally invasive approaches in selected patients with early gastric cancer. On the other hand, in patients with advanced or recurrent gastric cancer, the clinical outcome is poor owing to malignant characteristics. The 5-year survival rates in patients with stage IIIC and IV gastric cancer have been reported to be 20.2 and $8.8 \%$, respectively [2]. The Japanese Gastric Cancer Treatment Guidelines 2014 (ver. 4) have suggested chemotherapy for

(c) The Author(s). 2019 Open Access This article is distributed under the terms of the Creative Commons Attribution 4.0 International License (http://creativecommons.org/licenses/by/4.0/), which permits unrestricted use, distribution, and reproduction in any medium, provided you give appropriate credit to the original author(s) and the source, provide a link to the Creative Commons license, and indicate if changes were made. The Creative Commons Public Domain Dedication waiver (http://creativecommons.org/publicdomain/zero/1.0/) applies to the data made available in this article, unless otherwise stated. 
initial treatment in patients with unresectable or recurrent gastric cancer having a performance status of $0-2$ [3]. There has been focus on neoadjuvant chemotherapy (NAC) as a novel therapeutic strategy, and several studies have mentioned that NAC followed by gastrectomy is a promising approach to improve prognosis in patients with locally advanced gastric cancer [4-6]. Recent developments in chemotherapy are worthy of attention, and an improved prognosis is expected even in patients with advanced gastric cancer. However, it is clinically difficult to predict tumor response and prognosis before the initiation of chemotherapy. Thus, there are few prognostic predictors in the clinical management of patients with advanced gastric cancer.

To date, several investigators have demonstrated a close relationship between the systemic inflammatory response and tumor progression in various malignancies, including gastric cancer $[7,8]$. The neutrophil-lymphocyte ratio (NLR) and platelet-lymphocyte ratio (PLR) are representative blood markers of the systemic inflammatory response. We have previously reported that preoperative assessment of the NLR status has clinical utility for predicting tumor progression and prognosis in patients with resectable gastric carcinoma and esophageal squamous cell carcinoma $[9,10]$. Similarly, recent studies have shown that a high PLR is associated with tumor aggressiveness in patients with several neoplasms, including gastric cancer [11-14]. However, the clinical relevance of a new blood score that combines the NLR and PLR (NLR-PLR score) has not been assessed in patients with gastric cancer.

The purpose of the present study was to investigate the NLR and PLR before chemotherapy or chemoradiotherapy in patients with unresectable advanced and recurrent gastric cancer and to evaluate the relationship between tumor response and NLR/PLR. Furthermore, the study assessed the clinical potential of the NLR-PLR score as a new blood predictor of tumor response and prognosis.

\section{Methods}

\section{Patients}

The present study retrospectively enrolled 201 patients with unresectable advanced and recurrent gastric cancer who received chemotherapy or chemoradiotherapy at the Kagoshima University Hospital (Kagoshima, Japan) between January 2007 and December 2017. The exclusion criteria were as follows: synchronous or metachronous cancer in other organs $(n=4)$, absence of detailed therapeutic information $(n=7)$, and an unknown NLR or PLR $(n=15)$. Finally, 175 patients $(118$ men and 57 women; age range, 30-87 years; mean age, 65.8 years) were included in the present study (Fig. 1). Of the 175 patients, 150 and 25 patients had primary gastric tumors with distant metastasis and recurrent metastasis after gastrectomy, respectively. Among 175 patients with unresectable advanced and recurrent gastric cancer, 39 patients had more than 2 distant metastatic sites. Peritoneal dissemination, distant lymph node metastasis, and hematogenous metastasis were noted in 92, 63, and 51 patients, respectively. All patients underwent blood examinations, esophagogastroduodenoscopy, endoscopic ultrasonography, fluoroscopy, and computed tomography before chemotherapy or chemoradiotherapy. Furthermore, 160 patients underwent fluorodeoxyglucose positron emission tomography. Patients were classified and staged according to the tumor-node-metastasis classification for gastric carcinoma established by the International Union Against Cancer [15]. This retrospective observational study was approved by the Ethics Committee of the Kagoshima University (approval number: 28-37).

\section{Treatment and assessment of tumor response}

With regard to chemotherapy, 92 and 79 patients received cisplatin/fluoropyrimidine and paclitaxel/fluoropyrimidinebased chemotherapy as the first-line regimen, respectively. Additionally, 4 patients received cisplatin/fluoropyrimidinebased chemotherapy with concomitant radiation therapy at a total dose of 40-50 Gy.

The clinical responses were assessed after 2 or 3 cycles of chemotherapy or chemoradiotherapy. Tumor response was assessed using the Response Evaluation Criteria in Solid Tumors (RECIST), and it was categorized into progressive disease (PD) and non-PD [16]. Overall survival was calculated from the date of treatment initiation to the date of death or last follow-up.

Blood analysis for the determination of the NLR and PLR Blood samples were collected within 1 week before the initiation of chemotherapy or chemoradiotherapy. Neutrophils, lymphocytes, and platelets were counted using an XE-2100 automated hematology analyzer (Sysmex Co., Kobe, Japan). The NLR was determined as the neutrophil count divided by the lymphocyte count, while the PLR was determined as the platelet count divided by the lymphocyte count.

\section{Statistical analysis}

The differences in the associations between tumor response and the NLR or PLR were assessed using the Wilcoxon rank-sum test. Receiver operating characteristic (ROC) curves were constructed, and the areas under the curves (AUCs) were calculated to evaluate the predictive abilities of the NLR and PLR for discriminating patients with PD from those with non-PD. The relationships between tumor response and the NLR-PLR score were assessed using the $X^{2}$ test. Survival was analyzed using Kaplan-Meier curves, and prognostic differences 


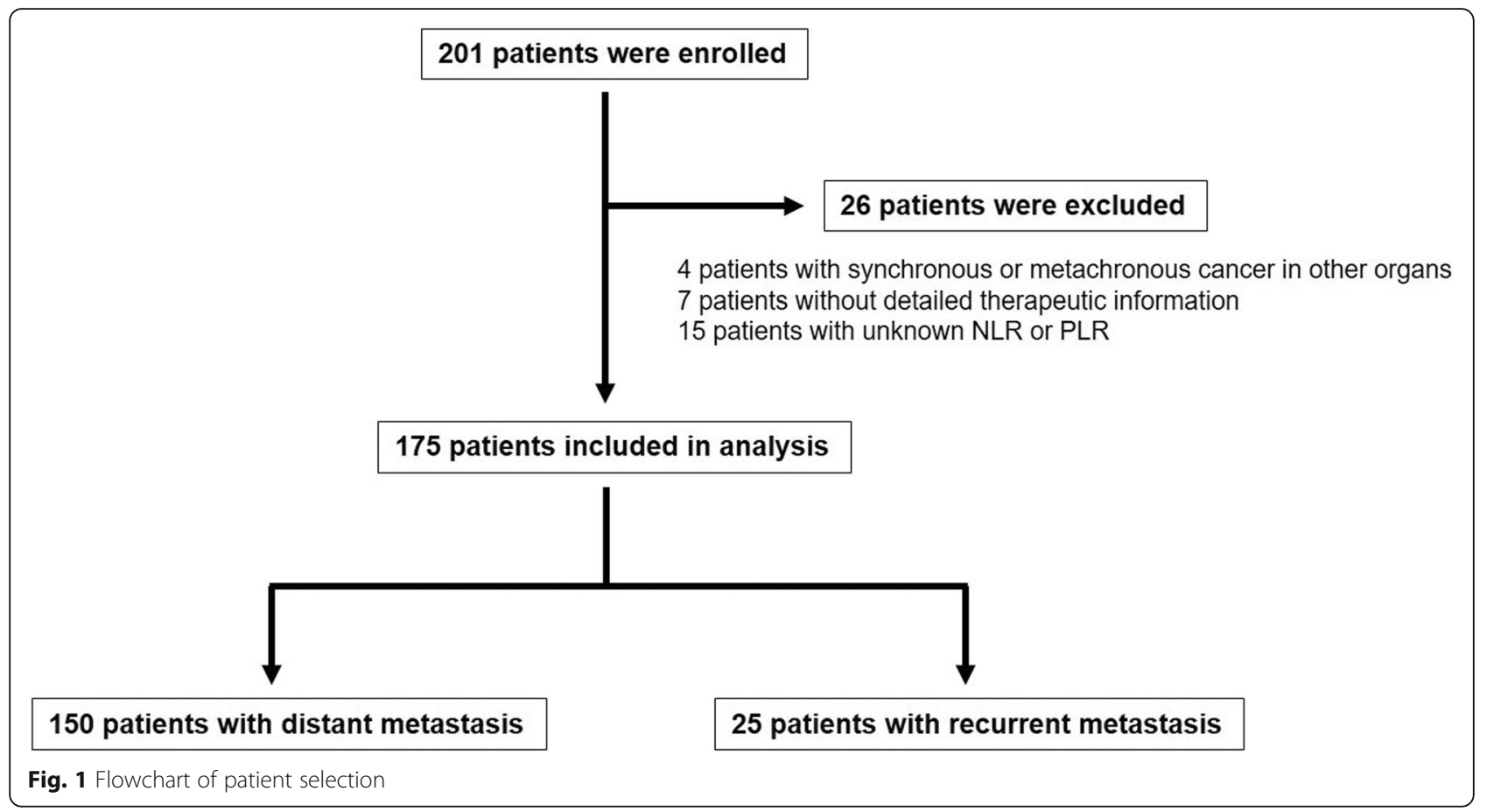

were examined using the log-rank test. Prognostic factors were assessed using univariate and multivariate analyses (Cox proportional hazard regression model). All statistical analyses were performed using SAS statistical software (SAS Institute Inc., Cary, NC, USA). A $p$ value of $<0.05$ was considered statistically significant.

\section{Results}

Tumor response after treatment and additional surgery According to the RECIST criteria, 64 and 111 patients had PD and non-PD, respectively. Consequently, the disease control rate was $63.4 \%$ (111/175). Additional surgery was performed in 2 and 45 patients with PD and non-PD, respectively.

\section{Relationship between tumor response and NLR/PLR}

Among the 175 patients, the NLR ranged from 0.534 to 30.333. The mean ( \pm SD) NLR in the 64 and 111 patients with PD and non-PD were $4.837 \pm 4.386$ and $3.090 \pm 1.602$, respectively (Fig. 2a). The NLR was significantly higher in patients with PD than in those with non-PD $(p=0.0006)$.

The PLR ranged from 1.2 to 873.3. The mean $( \pm$ SD) PLRs in the patients with PD and non-PD were $252.7 \pm$ 151.3 and $195.8 \pm 93.9$, respectively (Fig. 2b). The PLR was significantly higher in patients with $\mathrm{PD}$ than in those with non-PD $(p=0.0161)$.

In ROC analysis, the AUCs for discriminating patients with PD from those with non-PD according to the NLR and PLR were 0.656 and 0.609 , respectively (Fig. 3a and b). According to the findings of the ROC analysis, the cut-off values for the NLR and PLR were set at 2.461 and 248.4, respectively. The sensitivity and specificity for the NLR were 0.469 and 0.813 , respectively, while the sensitivity and specificity for the PLR were 0.775 and 0.453 , respectively. The patients were divided into the following groups according to the cut-off values of the NLR and PLR: high $(>2.461 ; n=107)$ and low NLR status $(\leq 2.461 ; n=68)$ or high $(>248.4 ; n=55)$ and low PLR status $(\leq 248.4 ; n=120)$. This binary system was used to determine the NLR-PLR score.

Relationship between tumor response and the NLR-PLR score The NLR-PLR score ranged from 0 to 2 as follows: score of 2, high NLR ( $>2.461)$ and high PLR ( $>248.4)$; score of 1 , either high NLR or high PLR; score of 0 , neither high NLR nor high PLR.

NLR-PLR scores of 0,1 , and 2 were noted in $60(34.3 \%)$, 68 (38.9\%), and 47 (26.9\%) patients, respectively. The NLR-PLR score was significantly higher in patients with PD than in those with non-PD $(p=0.0009)$ (Table 1$)$.

\section{Relationship between prognosis and the NLR-PLR score}

The median survival durations in patients with NLRPLR scores of 0,1 , and 2 were 827, 505, and 379 days, respectively (Fig. 4). Overall survival differences according to the NLR-PLR score were found to be significant $(p<0.0001)$.

Univariate analysis indicated that therapeutic type, tumor response, and NLR-PLR score were significantly associated with overall survival $(p=0.0227, p<0.0001$, and $p<0.0001$, respectively) (Table 2). Multivariate 


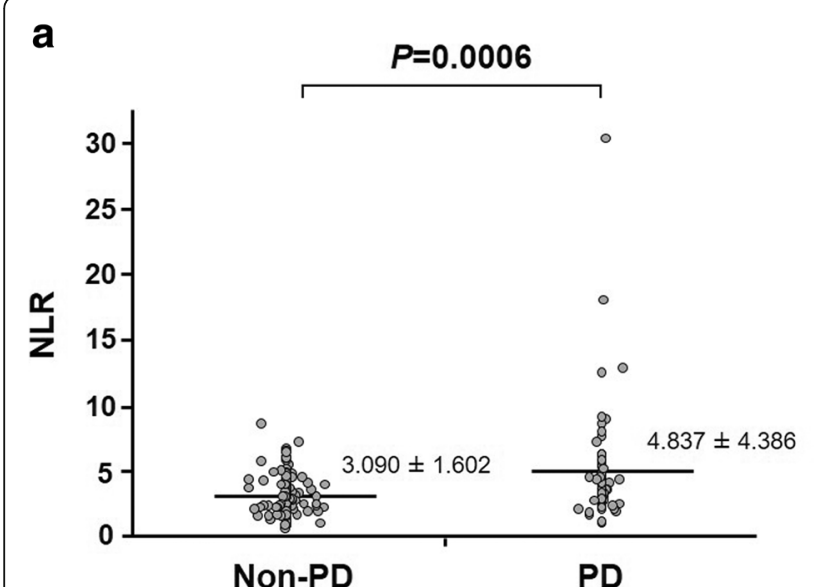

Tumor response

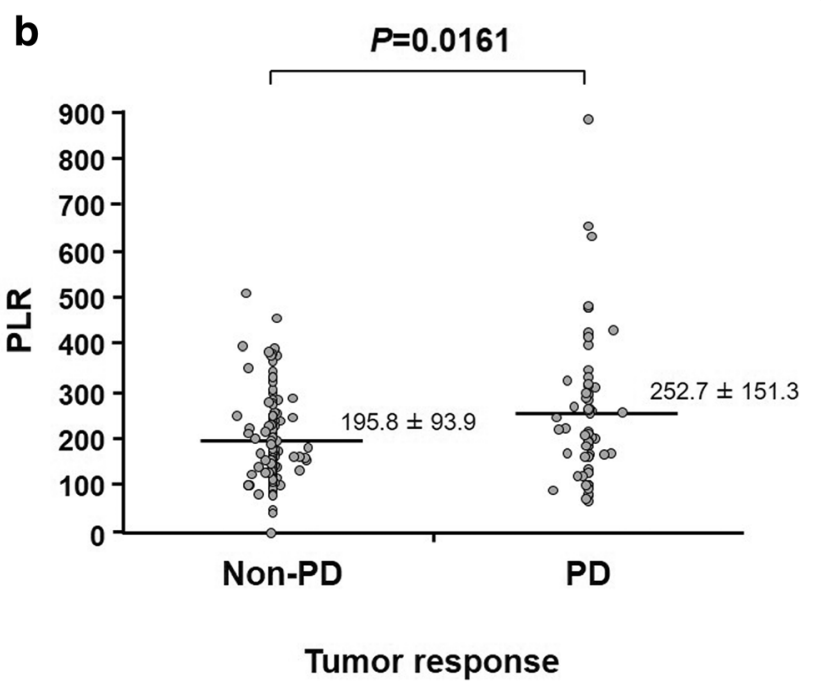

Fig. 2 Relationship between tumor response and the NLR (a)/PLR (b). Horizontal bars indicate mean values of the NLR and PLR analysis showed that tumor response and NLR-PLR score were independent prognostic factors $(p<0.0001$ and $p=0.0392$, respectively) (Table 2 ).

\section{Discussion}

Most previous studies have independently investigated the NLR and PLR and have assessed the clinical significance of these blood markers in patients with various malignancies, including gastric cancer [12, 17-22]. However, we combined the NLR and PLR and created the NLR-PLR score as a new scoring system for predicting tumor response and prognosis in patients with advanced or recurrent gastric cancer receiving chemotherapy. To the best of our knowledge, this is the first study to determine the clinical value of the NLR-PLR score in patients with gastric cancer.
Tumor response is one of the most important prognostic factors in patients with unresectable advanced or recurrent gastric cancer treated with chemotherapy or chemoradiotherapy. In the present study, the median survival rates of patients with PD and non-PD were 267 and 754 days, respectively (data not shown). This finding indicates the therapeutic requirement to distinguish responders from non-responders. Unfortunately, it is clinically difficult to predict tumor response using clinicopathological information before treatment. Therefore, we focused on the NLR and PLR to overcome issues with prediction. The NLR and PLR are well-known prognostic markers associated with the systemic inflammatory response, and the immune environment of the host has a great influence on these blood markers $[8,23]$. Initially, we examined the relationship between tumor response and the NLR/PLR to assess their
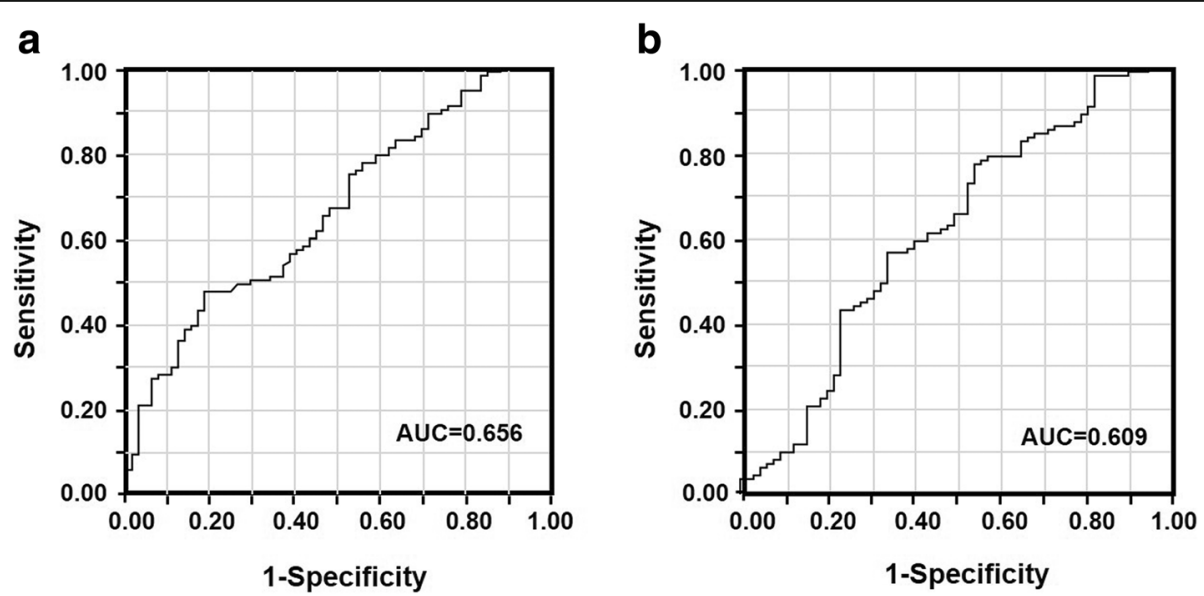

Fig. 3 Receiver operating characteristic curves for discriminating patients with PD and those with non-PD according to values of the neutrophillymphocyte ratio (a) and platelet-lymphocyte ratio (b) 
Table 1 Relationship between tumor response and the NLR-PLR score

\begin{tabular}{lllll}
\hline & \multicolumn{4}{l}{ NLR-PLR score $(\%)$} \\
\cline { 2 - 5 } Tumor response & $0(n=60)$ & $1(n=68)$ & $2(n=47)$ & $p$ value \\
\hline PD $(n=64)$ & $11(17.2)$ & $29(45.3)$ & $24(37.5)$ & 0.0009 \\
Non-PD $(n=111)$ & $49(44.1)$ & $39(35.1)$ & $23(20.7)$ & \\
\hline
\end{tabular}

$N L R$ neutrophil-lymphocyte ratio, $P D$ progressive disease, $P L R$ platelet-lymphocyte ratio

clinical potential as strategic blood markers in the management of patients with advanced gastric cancer. The present study demonstrated a close association between PD and a high NLR/PLR. Wang et al. assessed 120 patients with unresectable gastric cancer and reported that patients with a high baseline NLR/PLR had a significantly decreased response to chemotherapy [19]. These findings suggest that the NLR and PLR are candidate blood markers for discriminating between responders and non-responders among patients with unresectable gastric cancer.

In this study, we proposed the NLR-PLR score as a promising prognostic predictor. Surprisingly, the NLRPLR score was significantly associated with the tumor response to chemotherapy or chemoradiotherapy. Specifically, the NLR-PLR score was 2 in 24 of 64 patients (37.5\%) with PD and 0 in 49 of 111 patients (44.1\%) with non-PD. Moreover, a NLR-PLR score of 1 or 2 was common among patients with PD (82.8\%). These results indicate that the NLR-PLR score is clinically useful as a novel combined blood predictor of tumor response to first-line chemotherapy. Tumor cells produce cancerrelated inflammatory mediators, such as tumor necrosis factor- $\alpha$, interleukin-3 (IL-3), and IL-6 [24]. Next, these inflammatory response can result in a relative neutrophilia, thrombocytosis, and lymphocytopenia. Finally, these phenomenon causes elevated NLR and PLR $[9,10]$. Accordingly, high NLR-PLR score is associated with tumor aggressiveness. Since patients with high malignant behaviors have a tendency to chemoresistance [25], this study may indicate a close relationship between NLRPLR score and tumor response to chemotherapy.

We also evaluated the relation between the NLR-PLR score and prognosis in the same population. KaplanMeier analysis showed that the median survival duration was greater in patients with an NLR-PLR score of 0 than in those with an NLR-PLR score of 1 or 2. Accordingly, chemosensitivity might be higher in patients with an NLR-PLR score of 0 than in those with an NLR-PLR score of 1 or 2 . Moreover, the median survival durations in patients with NLR-PLR score of 0, low NLR, and low PLR were 827, 750, and 619 days, respectively (data not shown). These results may suggest that the NLR-PLR scoring system can discriminate patients with better prognosis after chemotherapy from all patients, compared with NLR or PLR alone. This would be the greatest advantage of the NLR-PLR score. NLR-PLR score and tumor response were identified as independent prognostic factors for prediction of overall survival in multivariate analysis. As tumor response is unknown before treatment, the NLR-PLR score is a potentially useful prognostic predictor that can be assessed before treatment. Therefore, the NLR-PLR score can help in the selection of patients who need chemotherapy or chemoradiotherapy for the clinical management of advanced gastric cancer. The NLR-PLR score can be easily

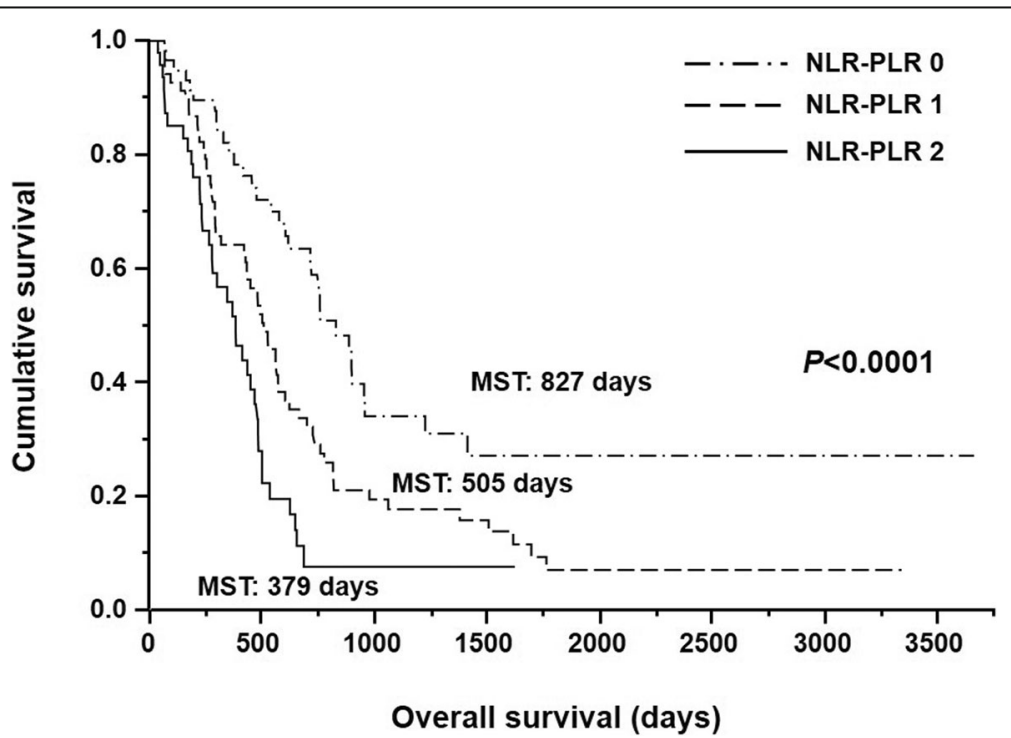

Fig. 4 Kaplan-Meier survival curves according to the NLR-PLR score. Survival is significantly poorer in patients with a high NLR-PLR score than in those with a low NLR-PLR score $(p<0.0001)$ 
Table 2 Univariate and multivariate analyses for survival

\begin{tabular}{|c|c|c|c|c|c|c|}
\hline \multirow[t]{2}{*}{ Independent factor } & \multicolumn{3}{|c|}{ Univariate analysis } & \multicolumn{3}{|c|}{ Multivariate analysis } \\
\hline & Hazard ratio & $95 \% \mathrm{Cl}$ & $p$ value & Hazard ratio & $95 \% \mathrm{Cl}$ & $p$ value \\
\hline Sex & & & 0.7321 & & & \\
\hline Female & 1.000 & reference & & & & \\
\hline Male & 1.066 & $0.742-1.557$ & & & & \\
\hline Age (years) & & & 0.2095 & & & \\
\hline$<70$ & 1.000 & reference & & & & \\
\hline$\geq 70$ & 1.257 & $0.878-1.786$ & & & & \\
\hline Therapeutic type & & & 0.0227 & & & 0.1226 \\
\hline Chemoradiotherapy & 1.000 & reference & & 1.000 & reference & \\
\hline Chemotherapy & 5.369 & $1.199-94.547$ & & 3.499 & $0.770-61.865$ & \\
\hline Tumor response & & & $<0.0001$ & & & $<0.0001$ \\
\hline Non-PD & 1.000 & reference & & 1.000 & reference & \\
\hline PD & 5.145 & $3.523-7.522$ & & 4.226 & $2.834-6.328$ & \\
\hline NLR-PLR score & & & $<0.0001$ & & & 0.0392 \\
\hline 0 & 1.000 & reference & & 1.000 & reference & \\
\hline 1 & 1.923 & $1.259-2.991$ & 0.0023 & 1.363 & $0.875-2.157$ & 0.1726 \\
\hline 2 & 3.296 & $2.027-5.390$ & $<0.0001$ & 1.958 & $1.167-3.299$ & 0.0110 \\
\hline
\end{tabular}

$C l$ confidence interval, $N L R$ neutrophil-lymphocyte ratio, $P D$ progressive disease, $P L R$ platelet-lymphocyte ratio

determined by calculating the NLR and PLR with a small volume of blood (only $2 \mathrm{ml}$ ). Thus, assessment of the NLR-PLR score is inexpensive.

The present study had several limitations. This preliminary study involved a retrospective analysis in a small population $(n=175)$ from a single institution. These limitations may have resulted in bias that might have influenced several study results. Consequently, larger validation studies are needed to confirm our findings. Currently, we are planning a further study to assess the clinical utility of the NLR-PLR score in patients with other malignancies, such as esophageal, hepatocellular, pancreatic, and colorectal cancer.

\section{Conclusions}

We demonstrated that the NLR-PLR score is a useful blood marker for predicting therapeutic responses to chemotherapy or chemoradiotherapy and survival outcomes in patients with unresectable advanced and recurrent gastric cancer. In the near future, we believe that the NLR-PLR scoring system will help in the decision-making of therapeutic strategies as a key marker in the clinical management of patients with advanced gastric cancer.

\section{Abbreviations}

AUCs: Areas under the curves; Cl: Confidence interval; NAC: Neoadjuvant chemotherapy; NLR: Neutrophil-lymphocyte ratio; PD: Progressive disease; PLR: Platelet-lymphocyte ratio; RECIST: Response Evaluation Criteria in Solid Tumors; ROC: Receiver operating characteristic
Authors' contributions

TH, TA, SY, DM, YU, YK, SM, KS, IO, HK, KM, KO, YU, SI and SN participated in the study design. TH, TA, SY, DM, YU, YK, SM and KS were involved in data collection and data interpretation. TH, TA, IO, HK, KM, KO, YU, SI and SN participated in the statistical analyses. TH, TA and SN wrote the manuscript. All authors read and approved the final manuscript.

\section{Funding}

No funding.

Availability of data and materials

The datasets used and/or analyzed during the current study are available from the corresponding author on reasonable request.

\section{Ethics approval and consent to participate}

This retrospective observational study was approved by the Ethics Committee of the Kagoshima University (approval number: 28-37). All patients provided written informed consent to the use and publication of their information.

\section{Consent for publication}

Not applicable.

\section{Competing interests}

The authors declare that they have no competing interests.

\section{Author details}

'Department of Digestive Surgery, Breast and Thyroid Surgery, Kagoshima University Graduate School of Medical and Dental Sciences, Kagoshima, Japan. ${ }^{2}$ Department of Onco-biological Surgery, Kagoshima University Graduate School of Medical and Dental Sciences, 8-35-1 Sakuragaoka, Kagoshima 890-8520, Japan.

Received: 28 December 2018 Accepted: 2 July 2019

Published online: 08 July 2019

\section{References}

1. Global Burden of Disease Cancer Collaboration, Fitzmaurice C, dicker D, pain a, Hamavid H, Moradi-Lakeh M, Maclntyre MF, Allen C, Hansen G, 
Woodbrook R, Wolfe C, Hamadeh RR, Moore a, Werdecker a, Gessner BD, Te Ao B, McMahon B, Karimkhani C, Yu C, Cooke GS, Schwebel DC, carpenter DO, Pereira DM, Nash D, Kazi DS, De Leo D, Plass D, Ukwaja KN, Thurston GD, Yun Jin K, Simard EP, Mills E, Park EK, Catalá-López F, deVeber G, Gotay C, khan G, Hosgood HD 3rd, Santos IS, Leasher JL, Singh J, Leigh J, Jonas JB, Sanabria J, Beardsley J, Jacobsen KH, Takahashi K, Franklin RC, Ronfani L, Montico M, Naldi L, Tonelli M, Geleijnse J, Petzold M, Shrime MG, Younis M, Yonemoto N, Breitborde N, yip P, Pourmalek F, Lotufo PA, Esteghamati a, Hankey GJ, Ali R, Lunevicius R, Malekzadeh R, Dellavalle R, Weintraub R, Lucas R, Hay R, Rojas-Rueda D, Westerman R, Sepanlou SG, Nolte S, Patten S, Weichenthal S, Abera SF, Fereshtehnejad SM, Shiue I, Driscoll T, Vasankari T, Alsharif U, Rahimi-Movaghar V, Vlassov W, Marcenes WS, Mekonnen W, Melaku YA, Yano Y, Artaman a, Campos I, MacLachlan J, Mueller U, Kim D, Trillini M, Eshrati B, Williams HC, Shibuya K, Dandona R, Murthy K, Cowie B, Amare AT, Antonio CA, Castañeda-Orjuela C, van Gool CH, Violante F, Oh $\mathrm{HH}_{\text {, }}$ Deribe K, Soreide K, Knibbs L, Kereselidze M, green M, Cardenas R, Roy N, Tillmann T, Li Y, Krueger H, Monasta L, Dey S, Sheikhbahaei S, Hafezi-Nejad N, Kumar GA, Sreeramareddy CT, Dandona L, Wang H, Vollset SE, Mokdad a, Salomon JA, Lozano R, Vos T, Forouzanfar M, Lopez a, Murray C, Naghavi M. The Global Burden of Cancer 2013. JAMA Oncol 2015;1:505-27.

2. Kim SG, Seo HS, Lee HH, Song KY, Park CH. Comparison of the differences in survival rates between the 7th and 8th editions of the AJCC TNM staging system for gastric adenocarcinoma: a single-institution study of 5,507 patients in Korea. J Gastric Cancer. 2017;17:212-9.

3. Japanese Gastric Cancer Association. Japanese gastric cancer treatment guidelines 2014 (ver. 4). Gastric Cancer 2017;20:1-19.

4. Al-Batran SE, Homann N, Pauligk C, Illerhaus G, Martens UM, Stoehlmacher J, Schmalenberg H, Luley KB, Prasnikar N, Egger M, Probst S, Messmann H, Moehler M, Fischbach W, Hartmann JT, Mayer F, Höffkes HG, Koenigsmann M, Arnold D, Kraus TW, Grimm K, Berkhoff S, Post S, Jäger E, Bechstein W, Ronellenfitsch U, Mönig S, Hofheinz RD. Effect of Neoadjuvant Chemotherapy Followed by Surgical Resection on Survival in Patients With Limited Metastatic Gastric or Gastroesophageal Junction Cancer: The AlOFLOT3 Trial. JAMA Oncol. 2017;3:1237-44.

5. Fitzgerald TL, Efird JT, Bellamy N, Russo SM, Jindal C, Mosquera C, Holliday EG, Biswas T. Perioperative chemotherapy versus postoperative chemoradiotherapy in patients with resectable gastric/gastroesophageal junction adenocarcinomas: A survival analysis of 5058 patients. Cancer. 2017;123:2909-17.

6. Li Y, Chen J, He Q, Ji X, Wang X, Fan C, Li G. Clinical efficacy of neoadjuvant chemotherapy regimens FLEEOX vs. XELOX in patients with initially unresectable advanced gastric cancer: a propensity score analysis. Oncotarget. 2017;8:86886-96

7. Diakos Cl, Charles KA, McMillan DC, Clarke SJ. Cancer-related inflammation and treatment effectiveness. Lancet Oncol. 2014;15:e493-503.

8. Roxburgh CS, McMillan DC. Cancer and systemic inflammation: treat the tumour and treat the host. Br J Cancer. 2014;110:1409-12.

9. Arigami T, Okumura H, Matsumoto M, Uchikado Y, Uenosono Y, Kita $Y$, Owaki T, Mori S, Kurahara H, Kijima Y, Ishigami S, Natsugoe S. Analysis of the Fibrinogen and Neutrophil-Lymphocyte Ratio in Esophageal Squamous Cell Carcinoma: A Promising Blood Marker of Tumor Progression and Prognosis. Medicine (Baltimore). 2015;94:e1702.

10. Arigami T, Uenosono Y, Matsushita D, Yanagita S, Uchikado Y, Kita Y, Mori S, Kijima Y, Okumura H, Maemura K, Ishigami S, Natsugoe S. Combined fibrinogen concentration and neutrophil-lymphocyte ratio as a prognostic marker of gastric cancer. Oncol Lett. 2016;11:1537-44.

11. Templeton AJ, Ace O, McNamara MG, Al-Mubarak M, Vera-Badillo FE, Hermanns T, Seruga B, Ocaña A, Tannock IF, Amir E. Prognostic role of platelet to lymphocyte ratio in solid tumors: a systematic review and metaanalysis. Cancer Epidemiol Biomark Prev. 2014;23:1204-12.

12. Yodying H, Matsuda A, Miyashita M, Matsumoto S, Sakurazawa N, Yamada M, Uchida E. Prognostic Significance of Neutrophil-to-Lymphocyte Ratio and Platelet-to-Lymphocyte Ratio in Oncologic Outcomes of Esophageal Cancer: A Systematic Review and Meta-analysis. Ann Surg Oncol. 2016;23:646-54.

13. Zhao QT, Yuan Z, Zhang H, Zhang XP, Wang HE, Wang ZK, Duan GC. Prognostic role of platelet to lymphocyte ratio in non-small cell lung cancers: A meta-analysis including 3,720 patients. Int J Cancer. 2016;139: 164-70.

14. Lu C, Gao P, Yang Y, Chen X, Wang L, Yu D, Song Y, Xu Q, Wang Z. Prognostic evaluation of platelet to lymphocyte ratio in patients with colorectal cancer. Oncotarget. 2017;8:86287-95.
15. Amin MB, Edge S, Greene F, Byrd DR, Brookland RK, Washington MK, Gershenwald JE, Compton CC, Hess KR, Sullivan DC, Jessup JM, Brierley JD, Gaspar LE, Schilsky RL, Balch CM, Winchester DP, Asare EA, Madera M, Gress DM, Meyer LR. AJCC Cancer staging manual, 8th edn. New York, NY: Springer; 2017.

16. Eisenhauer EA, Therasse P, Bogaerts J, Schwartz LH, Sargent D, Ford R, Dancey J, Arbuck S, Gwyther S, Mooney M, Rubinstein L, Shankar L, Dodd L, Kaplan R, Lacombe D, Verweij J. New response evaluation criteria in solid tumours: revised RECIST guideline (version 1.1). Eur J Cancer. 2009;45:228-47.

17. Lee S, Oh SY, Kim SH, Lee JH, Kim MC, Kim KH, Kim HJ. Prognostic significance of neutrophil lymphocyte ratio and platelet lymphocyte ratio in advanced gastric cancer patients treated with FOLFOX chemotherapy. BMC Cancer. 2013;13:350

18. Koh CH, Bhoo-Pathy N, Ng KL, Jabir RS, Tan GH, See MH, Jamaris S, Taib NA. Utility of pre-treatment neutrophil-lymphocyte ratio and plateletlymphocyte ratio as prognostic factors in breast cancer. Br J Cancer. 2015; 113:150-8.

19. Wang F, Liu ZY, Xia YY, Zhou C, Shen XM, Li XL, Han SG, Zheng Y, Mao ZQ, Gong FR, Tao M, Lian L, Li W. Changes in neutrophil/lymphocyte and platelet/lymphocyte ratios after chemotherapy correlate with chemotherapy response and prediction of prognosis in patients with unresectable gastric cancer. Oncol Lett. 2015;10:3411-8.

20. Chan JC, Chan DL, Diakos Cl, Engel A, Pavlakis N, Gill A, Clarke SJ. The Lymphocyte-to-Monocyte Ratio is a Superior Predictor of Overall Survival in Comparison to Established Biomarkers of Resectable Colorectal Cancer. Ann Surg. 2017;265:539-46.

21. Gemenetzis G, Bagante F, Griffin JF, Rezaee N, Javed AA, Manos LL, Lennon AM, Wood LD, Hruban RH, Zheng L, Zaheer A, Fishman EK, Ahuja N, Cameron JL, Weiss MJ, He J, Wolfgang CL. Neutrophil-to-lymphocyte Ratio is a Predictive Marker for Invasive Malignancy in Intraductal Papillary Mucinous Neoplasms of the Pancreas. Ann Surg. 2017;266:339-45.

22. Sierzega M, Lenart M, Rutkowska M, Surman M, Mytar B, Matyja A, Siedlar M, Kulig J. Preoperative neutrophil-lymphocyte and lymphocyte-monocyte ratios reflect immune cell population rearrangement in Resectable pancreatic Cancer. Ann Surg Oncol. 2017;24:808-15.

23. Dupré A, Malik HZ. Inflammation and cancer: What a surgical oncologist should know. Eur J Surg Oncol. 2018:44:566-70.

24. Hussain SP, Harris CC. Inflammation and cancer: an ancient link with novel potentials. Int J Cancer. 2007;121:2373-80.

25. Furukawa T, Tabata S, Yamamoto M, Kawahara K, Shinsato Y, Minami K, Shimokawa M, Akiyama SI. Thymidine phosphorylase in cancer aggressiveness and chemoresistance. Pharmacol Res. 2018;132:15-20.

\section{Publisher's Note}

Springer Nature remains neutral with regard to jurisdictional claims in published maps and institutional affiliations.

\section{Ready to submit your research? Choose BMC and benefit from:}

- fast, convenient online submission

- thorough peer review by experienced researchers in your field

- rapid publication on acceptance

- support for research data, including large and complex data types

- gold Open Access which fosters wider collaboration and increased citations

- maximum visibility for your research: over $100 \mathrm{M}$ website views per year

At BMC, research is always in progress.

Learn more biomedcentral.com/submissions 